\title{
Civis, hostis ac peregrinus - Representações da condição de homem livre no ordo iuris da Roma Antiga
}

\author{
Civis, hostis ac peregrines - Representations of the \\ condition of the free man in international ordo iuris of \\ Ancient Rome
}

\author{
Arno Dal Ri Jr.* \\ Luciene Dal $\mathrm{Ri}^{\star \star}$
}

\section{Resumo}

A "cidadania" romana surge como um conjunto de elementos que vinculam a pessoa a um determinado sistema jurídico, refletindo a relação entre o ser humano e a comunidade da qual participa. Essa relação é caracterizada em toda a existência de Roma pela liberdade de seus cives e é um dos principais instrumentos jurídicos utilizados nas relações com o interior e o exterior do povo romano. $\mathrm{O}$ instituto sofreu mudanças por meio da elaboração dos direitos de cidadania, e da modificação da política de abertura ao estrangeiro. A mudança de parâmetros em relação ao estrangeiro e o enrijecimento da concessão de cidadania são os temas deste trabalho, que investiga as causas externas e as consequências internas de tais fatos.

Palavras-chave: Cidadania. Cives. Estrangeiro. Roma Antiga.

Doutor em Direito Internacional pela Universidade Luigi Bocconi de Milão, com pós-doutorado pela Université Paris I (Panthéon-Sorbonne). Mestre em Direito e Política da União Europeia pela Universidade de Pádua. Professor de Teoria e História do Direito Internacional nos cursos de graduação e pós-graduação stricto sensu em Direito na Universidade Federal de Santa Catarina (UFSC). Florianópolis - SC - Brasil. E-mail: arno@ccj.ufsc.br.

** Doutora em Direito Civil romanístico pela Università degli Studi di Roma - La Sapienza. Mestre em Estudos Medievais pela Pontificia Università Antonianum. Professora de História do Direito no curso de graduação em Direito e no Programa de Pós-Graduação Stricto Sensu - Mestrado e Doutorado - em Ciência Jurídica na Universidade do Vale do Itajaí (UNIVALI). Itajaí - SC - Brasil. E-mail: luciene.dalri@univali.br. 


\section{Abstract}

The Roman "citizenship" emerges as a set of elements that bind the person to a particular legal system, reflecting the relationship among people and the community of which they participate. This relationship is characterized throughout the existence of Rome for the freedom of their cives and it is one of the main legal instruments used by Rome in the relations with the interior and the exterior of the Roman people. The institute has suffered changes through the development of citizenship rights and the modification of foreign politics openness. The change of parameters in relation to foreigners and the stiffness in the granting of citizenship are the themes of this contribution, which investigates the external causes and the internal consequences of such facts.

Keywords: Citizenship. Cives. Foreign. Ancient Rome.

Cum igitur hominum causa omne ius constitutum sit [...]

Herm. dig. 1.5.2

\section{Introdução}

Entre os mais significativos jurisconsultos de seu tempo, Hermogeniano afirmava que "o direito é constituído por causa dos homens". Forte no seu conteúdo, a frase contempla no direito o fenômeno regulador das relações sociais, das relações entre homens. A condição do ser humano no universo jurídico da Roma Antiga, ou seja, o status personae, manifesta-se como a forma de enquadramento normativo dos vários tipos de sujeitos que se abrigariam sob a expressão "pessoa"1. Rico nas suas nuances, o status personae pode ser analisado a partir de três ângulos diversos: o status libertatis, o status familiae, e o status civitatis. $\mathrm{O}$ enquadramento em cada situação jurídica se reflete nas próprias variáveis. Com isso, pode-se notar a existência de uma

Sobre a identificação entre homem e pessoa no direito romano, particularmente em Gaio, ver Lubrano (2002, p. 191 s.) 
concepção imersa em um sistema jurídico no qual todos os elementos estão interligados.

Dentre as situações jurídicas da pessoa, o status que sofreu maior variação de suas normas no tempo foi o status civitatis. Assim se deu em razão de ele ter sido um dos principais instrumentos jurídicos utilizados por Roma nas suas relações com o interior e com o exterior do povo romano, definindo quem é cidadão e, consequentemente, quem não o é. Observa-se, porém, que a abertura de Roma ao estrangeiro foi profundamente modificada entre o período final do reino e a metade do período republicano, enrijecendo a política de abertura ao estrangeiro e de concessão da cidadania, sem, para tanto, alterar o processo de expansão de Roma e de aumento da civitas, concebida como potencialmente universal.

A mudança de parâmetros na relação com o estrangeiro e o enrijecimento na política de concessão da cidadania são os temas deste trabalho, que investiga as causas externas e as consequências internas de tais fatos.

Para a compreensão dos institutos relativos ao status civitatis e, consequentemente, à participação na civitas, será utilizada uma abordagem das fontes romanas jurídicas e literárias. Dar-se-á, ainda, ênfase à terminologia utilizada, tomando em consideração o fértil debate da doutrina sobre o tema. Para uma melhor delimitação do civis, abordar-se-á, também, em contraponto à cidadania, a condição de "não romano", que abrange tanto o status jurídico de latinus quanto o status jurídico de peregrinus.

\section{Primeira construção da "cidadania"}

A Roma antiga apresenta nos conceitos de Quiris e civis, ligados intimamente às noções de status civitatis e civitas - elementos que vinculam o ser humano a um determinado sistema jurídico -, delineamentos que conduzem a uma "ideia de cidadania". Desse modo, portanto, o Quiris e, posteriormente, o civis seriam entendidos como 
parte do povo romano, unido pelo mesmo ius, gozando de certos direitos e incumbido de certos deveres.

O uso linguístico mais antigo para identificar a "pessoa parte" do populus Romanus Quirites ganha abrigo na expressão Quiris. A este se aplicava o ius Quiritium, particular esfera do ius concernente à cidadania ${ }^{2}$. A origem e a aplicação dos termos remetem ao período arcaico ${ }^{3}$.

O significado e a origem do termo Quiris são incertos, embora seja pacífica na doutrina a sua concepção como cidadão e antecedente histórico de civis. As passagens que tratam do termo Quiris denotamno como pessoa que participa do populus Romanus Quirites na sua universalidade, refletindo a parte e o todo.

A concepção de civis deve ser trabalhada em conjunto com a concepção de civitas, devido à origem e à intrínseca ligação existente entre os termos. A civitas era, inicialmente, a qualidade própria do cidadão, desenvolvendo, posteriormente, o significado de conjunto de cidadãos ${ }^{4}$. Fruto desse fenômeno, a construção da cidadania como instituto jurídico da Roma Antiga não é delineada apenas como uma ligação entre partes da comunidade, formando-a, mas é vinculada a um espaço geográfico de exercício de tais direitos. Será o território da

2 O conceito ius Quiritium será utilizado mesmo em fontes de idade imperial para indicar o direito de cidadania romana e, em particular, aquele concedido aos latinos, enquanto no caso da concessão aos peregrinos o termo mais usado era civitas romana. Catalano (1974, p. 146): "lus Quiritium e civitas Romana sono espressioni, riferentisi allo status di "cittadino" romano, cioè di parte del populus Romanus Quirites, le quali hanno origini storiche diverse. La prima espressione è certamente più antica (come Quiris è anteriore a civis) e risponde a una concezione di populus più concreta, in cui prevale l"aspetto della pluralità dei Quirites; la seconda, pur sempre concepita come ius omnium risente in qualche modo del processo di astrazione subito da populus in connessione al decadere dell'importanza politica e sociale dei comitia».

3 O período arcaido pode ser definido, segundo Orestano (1967), como o período que compreende a data tradicional da fundação de Roma e a Lei das XII Tábuas.

4 Dentro de uma análise semântica, Crifò (2004) teoriza que a passagem do significado de civitas como cidadão para o significado de conjunto de cidadãos e, posteriormente, cidade reflete a lógica de construção de Roma. A civitas romana é então concebida como uma organização social baseada na estrutura patriarcal-gentilícia religiosa, feita a partir do cidadão e para o cidadão. Ver: Crifò (2004, p. 24). 
cidade, o interior do pomerium, a dar concretude e materialidade a esse espaço. Por esse motivo, a concepção de cidadania no universo jurídico romano é intimamente ligada a um direito do cidadão à cidade ${ }^{5}$.

\subsection{A pertença à gens}

Desde as primeiras fases do período arcaico, um dos elementos de mais forte caracterização do civis romano encontra-se no fato de se pertencer ou não a uma gens romana. Consideradas organismos anteriores e constituidores da civitas, a gens e a família assumiam a condição de pressupostos políticos e sociais de Roma.

Os pressupostos de liberdade e de vínculo com Roma, concretizados no fato de se pertencer a uma gens, podem ser observados desde o período mais remoto da cidade. Eles são transmitidos através do nascimento, como delineia o jurista romano Gaio, na sua obra Institutiones. É muito claro, na exposição de Gaio, que o sistema jurídico romano era baseado no critério ius sanguinis para a concessão da cidadania, estendendo-a também por adoção, manumissão (concessão da liberdade ao escravo) e concessão individual ou coletiva.

\subsection{A pertença ao populus}

As diferentes interpretações dadas às fontes e ao termo populus em relação às suas partes (os cidadãos) e à constituição romana, com as suas consequências, fazem com que o estudo do tema se torne bastante complexo. As doutrinas alemãs e italianas, nesse âmbito, forneceram contribuições fundamentais para o debate, apresentando contrastes e intersecções, frutos de uma forte influência filosófica e política.

\footnotetext{
A afirmação de Crifò (2004) sobre o vínculo entre o instituto de cidadadania e o território romano é contraposta à de Gaudemet (2002, p. 180): "La citoyenneté dans la Rome classique n'implique aucune référence à une donnée territoriale". Cabe delinear, no confronto entre os dois autores, a ligação entre cidadania e território para o exercício de alguns direitos, como o ius suffragii e a provocatio ad populum (até o início do II a.C.). Pondera-se, porém, que a concessão da cidadania romana não encontra limites em origem e território, podendo ser adquirida por qualquer homem. Ver, a propósito da concepção espacial romana: Catalano (1978, p. 479 ss).
} 
Mesmo com tantas interpretações, a concepção do termo populus, em relação à sua origem filológica (poplus-), encontra-se pacificada na doutrina, sendo considerada como "multidão", também relativa a um "conjunto de homens armados"6. Deixando de lado a concepção política de povo, opta-se em centrar o debate no que concerne à composição e às prerrogativas do povo em assembleia, elementos que ainda são fonte de inúmeras controvérsias doutrinariais surgidas em teorias delineadas a partir do século XIX.

A composição do povo, no período arcaico, é apresentada pela doutrina através de duas correntes:

a) a primeira delas limita a concepção de povo ao conjunto de pessoas que teria a cidadania concedida somente ao elemento gentilício. Nesse sentido, o povo reunido em assembleia mantém o caráter gentilício desta, como acontece nas teorias propostas por Mommsen $(1887)^{7}$ e por De Martino (1973)

b) a segunda afirma a ausência, em época mais antiga do exclusivismo, da cidadania como elemento de composição do povo, conforme manifesta Bellini (1961). ${ }^{9}$ Com uma orientação diferente, mas sempre voluntarista, Catalano (2003), afirma a composição do populus

6 A origem indoeuropeia do termo é encontrada também junto aos umbros, através do termo poplo-. Sobre a definição latina de poplus e umbra de poplo-, teuta/tota-, ver: Catalano (1965, p. 486, nt. 144a ); Catalano (1974, p. 108 e ss.) especialmente p. 114, que indica Devoto (1954, p. 29 s). Diversamente, Coli (1958, p. 79 ss.); De Francisci (1959, p. 736).

7 Mommsen (1887, III, p. 3): "so dass die Bürgerschaft im rechtlichen Sinn gebildet wird durch die Gesammtheit der zur Zeit vorhandenen freien Geschlechtsgenossen, der quirites, später cives". O povo demonstra-se nessa interpretação como soberano e investe o rei no seu poder, assimilável a uma magistratura única e vitalícia. A plebe passou a participar ativamente das decisões tomadas em assembleia somente com a reforma serviana. Ver: Carle (1888, p. 180 ss.) e Costa (1906, p. 49).

8 De Martino (1973, I, p. 89 ss.): "Entrambi i organi di questa primitiva comunità di villaggio erano esclusivamente patrizi, il che significa che il popolo era costituito ancora soltanto da coloro che appartenevano ai grandi gruppi gentilizi."

9 A interpretação de Bellini identifica-se com alguns aspectos da de Jhering (1880), a qual, partindo da tradição relativa à origem de Roma, entende o povo romano como formado por homens provenientes de diferentes origens. 
por homens que vivem de acordo com o direito romano ${ }^{10}$. Nesse sentido também se manifesta Amirante (1991)11, ao afirmar que a aplicação do conceito de cives se expande aos latinos, devido à comunhão entre direito e religião.

A hipótese sustentada por Mommsen (1887) e por De Martino (1973), afirmando a fundação da cidade com a divisão da população em duas categorias (plebeia e patrícia), sendo a plebe excluída da cidadania por não pertencer à federação originária das gentes, não encontra respaldo nas fontes que tratam do período régio. O próprio De Martino (1973) reconhece que a sua proposta de estrutura federativa é incompatível com a tradição da fundação de Roma.

Plutarco, Floro, Lactâncio, Eutrópio, Agostinho e Columela, ao tratarem da fundação da cidade e da formação do povo romano, prescindem do elemento gentilício e não tratam de cidadania ${ }^{12}$.

O conceito de povo vem então proposto como "uma 'multidão' com certas características. Não se trata de uma coisa 'personificada', como o 'Estado"' (CATALANO, 2003, p. 101). O "povo" passa a ser apresentado como algo concreto, permitindo uma abstração somente enquanto unidade, ou seja, conjunto de homens. Não se condiciona pelo elemento gentilício como portador de cidadania, mas se fundamenta no

10 Como consequência dessa concepção, o direito romano não é feito para os cidadãos romanos, mas para os homens, evidenciando o seu universalismo. Em contrapartida, constata o autor uma forte política de concessão da cidadania que concebe o "ser romano" através do viver de acordo com os costumes e a cultura romana. Ver: Cic. rep. 1,39 e Alf. dig. 5,1,76.

11 Luigi Amirante (1991, p. 109 ss.) baseando-se no relato de Lívio e Strabão, analisa a aceitação de estrangeiros como reis de Roma e conclui que: "Non potrebbe essere più chiaro che qui peregrinus sta ad indicare colui che non è latino, che appartiene ad altro diritto e ad altri culti. $E$ per converso come cives 'concittadini', coloro che hanno in comune diritti e religione."

12 Plutarco (Rom. 9,3), Floro (Epit. 1,1,9), Lactâncio (inst. 2,6), Eutrópio (Brev. 2,1), Agostinho (civ. 1,34) e Columela (r.r. 1 praef. 18). De forma pouco clara, Dionísio de Halicarnasso $(2,9,2)$ afirma que Rômulo confiou os plebeus aos patrícios, não identificando a composição das duas categorias. Sobre cidadania romana, ver Crifò (1960, p. 1 ss.; CRIFÒ, 2003, p. 23 ss.). Sobre Asilo: Crifò (1958, p. 191 ss.). 
voluntarismo da multidão e, consequentemente, dos homens em viver de acordo com o direito romano ${ }^{13}$.

O termo "multidão" denota o reconhecimento de todos os seres humanos (homens e mulheres) como parte do populus. Tal fato, somado à abertura da comunidade dentro da Liga Latina ainda em tardo período régio, demonstra independência em relação a um conceito exclusivista ou étnico de cidadania. Esta, no período arcaico, era baseada em uma concepção universalista ou voluntarista, que reconhecia aos habitantes de Roma, independentemente de suas origens, a possibilidade de fazerem parte do direito romano ${ }^{14}$. Nesse sentido, Bellini $(1961)^{15}$ afirma que havia, originariamente, uma relação de igualdade entre as comunidades, permitindo um contínuo intercâmbio dos seus elementos constitutivos.

13 Sêneca (ira, 2,31,7) transcende a cidadania através do universalismo, ao tratar da pátria com base na concepção de pertença a uma "cidade" ainda maior: "Nefas est nocere patriae; ergo ciui quoque, nam hic pars patriae est - sanctae partes sunt, si uniuersum uenerabile est; ergo et homini, nam hic in maiore tibi urbe ciuis est. Quid si nocere uelint manus pedibus, manibus oculi? $V t$ omnia inter se membra consentiunt quia singula seruari totius interest, ita homines singulis parcent quia ad coetum geniti sunt, salua autem esse societas nisi custodia et amore partium non potest". Nesse sentido, o jurista Alfeno (dig. $5,1,76$ ) compara o povo a um corpo, que, pela sua espécie, define-se como tal, independentemente da mudança de suas partes.

14 Essa mesma concepção universalista, embora com novos instrumentos, se fará presente em 212 d.C. com o edito de Antonino Caracala, que expande a cidadania, salvo exceções, a todos os habitantes do império.

15 Bellini (1961, p. 226): "Nell'assenza per l'epoca più antica di un esclusivismo cittadino (che solo lentamente si verrà maturando), le comunità tribali si trovano su un piede di parità, che permette un continuo interscambio dei loro elementi. Dei re di Roma, escludendo i mitici fondatori Albani, Tullo è di Medulia, Numa e Anco di Cures. Assumendo che sotto i fatti storici si nasconda un fondamento storico, può supporsi che cosi si localizzassero nell'oppidum romano capi di formazione più vaste, comprensive delle località di origine, ovvero che il sentimento comunitario rendesse facile l'interscambio degli elementi dirigenti: probabilmente le due cose allo stesso tempo, in una realtà che può suporsi fluida e non definita. [...] sotto questo punto di vista il lus Latii dell'epoca storica non sarebbe la condizionata e limitata estensione alle comunità sociae dei diritti della civitas, ma è il sopravvivere di un'eguaglianza sociale che, al sovvraporsi della organizzazione cittadina e nel processo di giuridicizzazione del costume, permane sotto la forma di un privilegio concesso dalla città egemone." O autor indica como trabalho anterior, com a mesma concepção: Sherwin White (1939). Concordando com Bellini sobre a fluidez do "stato di cittadinanza", Serrao (2006). Em contraposição, Ellul (1999) entende que a igualdade ocorre somente entre as cidades latinas desde o início por conta da origem religiosa em comum. Os latinos, provenientes de Alba, têm instituições próximas que os permitem usar um direito comum. 
Tal teoria implica na ausência, em época mais antiga, de uma imposição racial no que concerne à cidadania. Ser cidadão "implica a vontade política que faz de um homem um quirite, ou seja, torna-o parte do populus Romanus Quirites" (CATALANO, 1982, p. XXII; 2003, p. 101 $)^{16}$. É, consequentemente, viver de acordo com o direito romano. Com isso, Roma passa a valorizar, então, uma forte política de concessão da cidadania baseada no viver de acordo com o direito e a cultura romana ${ }^{17}$.

Os princípios de civitas augescens e civitas amplianda estariam presentes no universalismo romano - para a concessão da cidadania através do instituto de asilo de Rômulo, no Capitólio ${ }^{18}$, manifestando-se também na manumissio dos escravos, bem como no fato de a plebe ser vista como conjunto de homens não ligados a nenhuma gens, também como cives e, portanto, como parte do povo (CATALANO, 2007; 1974, p. 116 ss.; 1982, p. XXII s.). Tal fenômeno faz com que o elemento voluntarista, presente a partir da fundação de Roma - voltado sobretudo à construção de um povo constituído pelo conjunto de cidadãos -, conduza a uma concepção universalista de cidadania, que, por sua vez, gera uma concepção universalista do direito romano, feito não somente para os cidadãos romanos, mas para os homens.

Essa concepção sofreu modificações a partir do final do reino e metade da república. Nesse período, o reconhecimento de igualdade entre os elementos das comunidades passou a ocorrer apenas entre latinos, revestindo-se daquilo que se tornaria o ius latii. Tem-se, dessa

16 Ver Cic. rep. 1,39 e Alf. dig. 5,1,76.

17 Nesse sentido também se manifesta Amirante (1991, p. 109 ss.), ao afirmar que a aplicação do conceito de cives se expande aos latinos devido à comunhão de direito e religião. Baseando-se no relato de Lívio e Strabão, analisa a aceitação de estrangeiros como reis de Roma e conclui que: "Non potrebbe essere più chiaro che qui peregrinus sta ad indicare colui che non è latino, che appartiene ad altro diritto e ad altri culti. E per converso come cives 'concittadini', coloro che hanno in comune diritti e religione."

18 Liv. 1, 8, 4. O "asilo no Capitólio" foi criado por Rômulo para a concessão da cidadania às pessoas estrangeiras, em geral banidas ou fugidas das cidades vizinhas, e visava aumentar a população de Roma. 
forma, uma nova concepção de civitas, com a consolidação da unidade composta pelas partes ${ }^{19}$. Mesmo com essa limitação, permanecem indícios da abertura originária do sistema romano através da Lei das XII Tábuas, denotando a participação do estrangeiro ao ius ${ }^{20}$.

\section{As guerras de expansão romana e o enrijecimento da assimilação do estrangeiro}

Uma análise exaustiva do conceito de cidadania em Roma deve levar em conta, ainda, o seu contraponto conceitual, ou seja, o status de quem não era cidadão romano. O termo mais antigo usado para indicar o estrangeiro era hostis. Na sua origem, esse conceito não apresentava conotação negativa, tratando apenas da constatação da não pertença de alguém à comunidade romana ${ }^{21}$.

Pesquisas recentes ${ }^{22}$ têm evidenciado a existência de diferentes teses quanto à tutela jurídica prestada ao estrangeiro no âmbito do sistema jurídico romano. Primeiro, tem-se a tese da hostilidade natural, que remonta a Mommsen, asseverando que, em época primitiva, estava em vigor o princípio da ausência de direito do estrangeiro fora dos limites da sua cidade. Tal princípio somente sofreria uma flexibilização através do instituto de hospitium privado. Em posição contrária, autores

19 Assim, a ideologia de uma comunidade unitária encontra suas raízes no mundo etrusco, sendo posteriormente transmitida para Roma (SERRAO, 1975; NOCERA, 1992). Tondo (1981) afirma que populus e plebs apresentam-se, então, como aspectos militar e social do mesmo elemento constitucional; povo e senado apresentam-se como elementos fundamentais para o enquadramento da população romana. Com diferente leitura sobre a expressão populus plebesque, Catalano (1974a, p. 682): "populus plebesque indica il crescente potere della parte plebea, populus plebesque la raggiunta parificazione sul piano del potere normativo e cioè l'assimilazione della 'parte' nel 'tutto". A teoria afirmada por Tondo (1981) remonta, de certa forma, àquela de Niebuhr, que interpreta a expressão populus Romanus Quirites com idêntico significado de populus plebes que Romana. Como manifesta Catalano (populus Romanus Quirites, p. 24), o Niebuhr usa "Volk» seja para indicar a plebs, seja para indicar a multidão (NIEBUHR, 1811).

20 Gell. noct. att. 20,1,47 (FIRA, tab. III, 5); "tratados" que limitavam o comércio (como aquele de Cartago) e Festus, Status dies p. 314 L. Sobre o assunto, ver: Catalano (1965, p. 66 ss; 1974, p. $140 \mathrm{ss})$.

21 Ver: Ernout et Meillet (1, p. 301) e Benveniste (1969, I, p. 93).

22 Catalano (1965, p. 53 ss.). 
como Frezza rejeitam a tese de hostilidade natural, mas entendem que havia restrições aos estrangeiros antes do século III a.C. Uma terceira posição, representada por Heuss, afirma a existência de um comércio internacional com ausência de tratados. Nessa direção afirma também De Martino, ou seja, de que, tendo por base a fides, o estrangeiro poderia ser juridicamente tutelado. Com relação ao período mais antigo, tendo por base pesquisas sobre o ius fetiale, não haveria, para os romanos, a impossibilidade de que os estrangeiros, mesmo não ligados a Roma por tratados, fossem sujeitos de atos solenes e relações consideradas pelo ius (CATALANO, 1965).

Nesse período, formado pela comunidade gentilícia até a consolidação da civitas, entende-se que provavelmente não houve uma clara distinção, do ponto de vista jurídico, entre cidadão e estrangeiro, sendo possível que este viesse a fazer parte ao ius. Assim sendo, o ius romano, baseado na sua natureza universalista, abarcaria tanto cidadãos quanto estrangeiros, dentro de uma maior ou menor tutela, de acordo com a existência ou não de particulares foedus ${ }^{23}$. Essa concepção jurídica de direitos do estrangeiro pode ainda ser encontrada na Lei das XII Tábuas ${ }^{24}$, assim como se encontra nos escritos de Gélio (noct. att. 16,4,4.) e de Festo (v. Status dies <cum hoste> pp. 414-416 L.).

$\mathrm{Na}$ época mais antiga o estrangeiro em geral era indicado como hostis, enquanto o 'inimigo' era perduellis. Somente em um segundo momento o estrangeiro será designado como peregrinus e se afirmará o uso de hostis no sentido de 'inimigo', ou seja, de indivíduo parte em uma situação de guerra com Roma. (SERRAO, 2006, p. 344) ${ }^{25}$

23 Ver sobre o tema foedus Cassianum entre romanos e latinos, em 493 a.C., e os dois tratados de Roma com Cartago, em 509 a.C. e 348 a.C. De forma contrária, Colognesi (2004, p. 79) entende que o forte interesse das partes no Tratado de Cartago em prover a tutela dos seus cidadãos que venham a se encontrar no âmbito de influência da contraparte, "mostra tuttavia che solo un apposito accordo internazionale poteva vincolare gli ordinamentistatali dell'epoca a fornire una adeguata protezione giuridica agli stranieri".

24 Ver Tab. I,5; II,2: VI,4.

25 Tradução livre dos autores. 
A abertura de Roma ao estrangeiro, fruto da cultura universalista também presente no ius e que facilitava a concessão da cidadania romana, foi indicada por Lívio através do Asilo no Capitólio (Liv. 1,8,4) e da própria formação da cidade. Tal abertura, contudo, provavelmente foi modificada entre o final do reino e a metade da república. Observa-se tal fato devido à mudança no significado do termo hostis, que, inicialmente, significava "estrangeiro", passando, com o tempo, a adquirir outro significado, o de "inimigo".

Segundo De Martino (1973), uma hipótese relativa a essa mudança é o longo período de guerras de expansão nas quais Roma esteve envolvida. Isso provavelmente acabou por desencadear um processo que conduziu a um rompimento com a abertura ao estrangeiro, afetando, consequentemente, a política flexível de concessão da cidadania. A mudança é atribuída ao período posterior à emanação das XII Tábuas, provavelmente nos anos das guerras de expansão na Itália, evidenciando a impossibilidade de especificar como e por quais causas tal fenômeno ocorreu ${ }^{26}$.

O gênero "não cidadão" demonstra-se, portanto, constituído por diferentes espécies: o estrangeiro que não pertencia a um povo em guerra com Roma e que não era ligado a Roma por um particular tratado ou vínculo étnico; o estrangeiro ligado a Roma pelos foedera; os grupos que, por circunstâncias e motivos diferentes, tinham encontrado asilo na cidade; e os habitantes das cidades latinas ligadas a Roma por tratados e vínculos étnicos, aos quais era reservada uma posição privilegiada, visto que constituíam um status intermediário entre cives e peregrini, com subdivisões no que se refere ao exercício de direitos (SERRAO, $2006)^{27}$.

\footnotetext{
26 Sobre a mudança de significado do termo hostis, ver: Benveniste (1969, p. 93).

27 Várias eram as distinções quanto aos peregrinos no que se refere às limitações ao exercício de direitos. Aos possuidores de melhores condições, era reconhecido o direito ao commercium e ao connubium com os romanos e latinos, assim como o direito ao testamenti factio, ou seja, de ser nomeado herdeiro de testamento de um cidadão romano. Por serem considerados, para todos os efeitos, estrangeiros, em sua maioria, os peregrini não estavam sujeitos ao direito romano, mas sim ao ius gentium aplicado pelo pretor peregrino. Ver: Stadtmüller (1951, p. 34).
} 
Esse mosaico de relações pode ser mais facilmente compreendido se partirmos da constatação de que, no período republicano, a distinção do status jurídico das pessoas em relação ao povo romano era de três tipos: cives Romani, ou seja, todos aqueles reconhecidos como cidadãos romanos; latini, habitantes das cidades latinas que faziam parte do foedus latinum; e peregrini, estrangeiros e, consequentemente, pessoas que não fossem cives ou latini (CERAMI; CORBINO, 1996).

É possível observar a modificação dos requisitos para a concessão da cidadania romana, passando a ser regulada da seguinte forma:

Por nascimento:

- de um casamento válido, sendo o pai cidadão romano no momento da concepção, mesmo que a mãe não seja cidadã28;

- de mãe romana, ainda que fora de um casamento válido. Se a criança não nasceu de um casamento válido, de acordo com o direito romano, ela segue a condição jurídica da mãe ${ }^{29}$;

"O que temos falado a respeito do fato que aquele que nasce de uma cidadã Romana e de um peregrinus, entre os quais não existe matrimônio, nasce peregrinus, é estabelecido pela Lei Mincia. Esta dispõe, também, que este segue a condição do genitor mais desavantajado. A mesma lei, de fato, dispõe que, quando, ao contrário, um peregrinus tenha pego como esposa uma cidadã Romana com a qual não existia matrimônio, aquele que nasce de uma tal união seja peregrinus. A Lei Mincia é particularmente oportuna neste caso: na ausência desta lei, de fato, seria indevido derivar um outro status. Já o que nasce daqueles entre os quais não existe matrimônio aquista o status da mãe, segundo o direito das gentes. Mas, é supérflua aquela parte da lei onde vem estabelecido que, de um cidadão Romano e de uma peregrinus, nasce um peregrinus. Este, de fato, seria peregrinus segundo o direito das gentes também na ausência de tal lei. Isto vale somente para as nações e as gentes estrangeiras, mas também para quantos são chamados Latini, que tinham próprios povos e próprias cidades e eram contados entre os peregrini. Pelo mesmo motivo, ao contrário, nasce um cidadão Romano de um Latino e de uma cidadã Romana, seja o matrimônio contraído em base a Lei Elia Senzia seja de outro modo. Mas, alguns tiveram que, de um matrimônio contraído em base a Lei Elia Senzia, nascesse um Latino, já que se considerava que, neste caso, o matrimônio entre eles fosse concedido pelas Leis Elia Senzia e lunia e que, sempre, o matrimônio faz com que aquele que nasce siga o status do pai. Quando, ao invés, o matrimônio tenha sido contraído de outro modo, aquele que nasce, segundo o direito das gentes, segue o status da mãe, e é, por tanto, cidadão Romano. Mas, segundo o direito vigente em base a um senatoconsulto emanado por proposta do divo Adriano, aquele que nasce de um Latino e de uma cidadã Romana é de qualquer modo cidadão Romano" (Gai. inst. 1,78-80).

29 Conforme nos lembra Crifò (2004, p. 33), nos casos em que o filho segue a condição da mãe: "è cittadino se la madre è cittadina al momento del parto, non lo è se la madre lo era in gravidanza, ma ha cessato di esserlo al momento del parto, nè lo sarà, alla fine della repubblica, se nasce da una cittadina e da un Latino o peregrino (Lex Minicia)". 
- ao filho de peregrinos se, antes do nascimento, for concedida a cidadania a ambos os genitores, ou somente ao pai; ou se a mãe tiver obtido ao menos o connubium, condição necessária para o matrimônio legítimo.

Após o nascimento:

- por concessão individual e estritamente pessoal;

- por concessão coletiva;

- por consequência automática de certas condições, como o domicílio em Roma;

- por manumissão por parte do dominus.

O aumento do campo de regulação das normas voltadas à concessão da cidadania reflete não apenas o enrijecimento da relação com o estrangeiro, como a maior preocupação no que se refere aos direitos concernentes à cidadania, levando até mesmo à guerra de Roma com seus aliados.

\section{A liberdade como pressuposto da cidadania}

A liberdade, para os romanos, é uma condição presente desde o direito natural, sendo considerada pressuposto de cidadania. Um homem livre pode não ser cidadão, mas todo cidadão é obrigatoriamente um homem livre. A origem da palavra libertas testemunharia essa ligação. Conforme Crifó (1984, p. 22), libersignifica "aquele que pertence à estirpe" e libertas, enquanto condição de livre, deveria indicar o complexo das faculdades que a estirpe reconhece ao seu componente. A liberdade, no âmbito da cidadania, reveste-se de um significado jurídico e político. $O$ significado político está na sua ligação com a civitas e a participação ao poder político, implicando a liberdade do povo romano na sua totalidade diante de uma ameaça externa ou interna. A liberdade não política, por sua vez, seria estabelecida pelo direito e necessariamente limitada, correspondendo à ideia de autonomia grega. Trata-se da liberdade como consequência de ser cidadão romano. A civitas romana, como 
é possível constatar, encontra-se intrinsecamente ligada à noção de liberdade, garantindo, através do ius, a sua conservação aos cidadãos e aos povos submissos a Roma. A civitas romana representa, portanto, um conjunto de homens livres.

Dentre as liberdades de direito, são garantidas ao cidadão o direito a contrair matrimônio válido com pessoa romana ou latina, o direito à tutela dos atos de comércio e o direito ao voto. A liberdade gerava ao romano e ao estrangeiro o direito de não ser submetido a todo e qualquer tipo de tortura. De acordo com o sistema jurídico romano, o homem livre não pode ser flagelado, apenas receber chibatadas.

Os aspectos político e jurídico da liberdade romana não implicariam, porém, em uma ideia de igualdade. Como delineado por Crifò (1984, p. 22), "Roma dá à liberdade uma extensão e um conteúdo jurídico diferentes, segundo a classe social e a categoria à qual pertencem os indivíduos, classe e categoria para as quais é assegurada uma larga mobilidade" 30 .

A diferente extensão de direitos reflete-se no fato de que as pessoas pertencentes à plebe possuem um conjunto de direitos menor do que aqueles pertencentes ao patriciado. A diferença no conteúdo observa-se na diversa graduação de valor atribuído ao voto de cada cidadão. Dessa forma, todos tinham direito ao voto, mas a efetiva participação no poder público era diferenciada, tendo as classes mais elevadas a maioria dos votos e, consequentemente, um poder muito maior. Tal distinção na participação política, embora marcante, não é constatável desde a fundação da cidade, mas instaurada apenas com a dinastia Tarquínia, pelo rei Sérvio Túlio, e mantida durante toda a república, tendo suas bases em fatores como a economia, o nascimento e a carreira (Liv. 1,43,10).

30 Tradução livre dos autores. 


\section{Direitos e obrigações do cidadão romano}

O vínculo entre cidadania e liberdade pode ser constatado no caso de escravos fugitivos de outras cidades que pediam asilo no Capitólio. Devido a esse instituto, os escravos asilados recebiam, junto com a cidadania, o status de homem livre. O mesmo se dava nos casos de manumissio, em que o ser humano recebia, junto com a liberdade, a cidadania.

As prerrogativas de ser cidadão implicam liberdade política e liberdade de direito, denotando a importância da instituição de cidadania, bem como evidenciando o interesse gerado por esta durante toda a história de Roma. Como delineia Crifò $(2004)^{31}$, quem é reconhecido como cidadão pode tornar-se chefe de família, sendo titular da patria potestas, da manus sobre as mulheres e do dominium sobre coisas e escravos. Como cidadão e pater familias, pode manumitir escravos, instituir culto privado, oferecer proteção e assistência a estrangeiros e concidadãos, realizar negócios jurídicos intervivos, instituir e ser instituído herdeiro em um testamento, suceder ab intestato, arrogar, adotar, emancipar, ser tutor. Pode agir processualmente, votar nas assembleias populares e participar das decisões sobre a paz e sobre a guerra, sobre concessões ou não da liberdade, sobre eleições de magistrados, sobre exército, tributos, vida dos compatriotas, honras e triunfos. Pode exercitar ações populares, ser juízes nos processos civis e jurado nos criminais, ser eleito magistrado, exercitar o ius militiae, fazer parte dos colégios sacerdotais, colher auspícios, fundar uma tumba, exercitar o ius provocationis e subtrair-se, através do exilium, da pena capital.

A cidadania romana, em seu aspecto jurídico, permitiu a afirmação de instrumentos para proteger o cidadão romano das arbitrariedades dos magistrados, limitando fortemente o exercício do poder da magistratura diante dos membros da comunidade. Um desses instrumentos é a provocatio ad populum (também conhecida como ius provocationis)

${ }^{31}$ Em linha levemente diversa Gaudemet (2002, p. 183). 
(GROSSO, 1997). ${ }^{32}$ A provocatio é um instituto jurídico típico do período republicano e consistia na apelação ao povo, objetivando impedir a execução de uma condenação penal emanada por magistrado. Durante o império, ela também protegia o cidadão da fustigação, da tortura e da reclusão ${ }^{33}$. Tal instituto foi inicialmente proposto com previsão de uso restrito aos limites da cidade de Roma. Apenas a partir de uma das Leges Porciae de provocatione, no início do século II a.C., passou a ser permitido o uso da provocatio fora dos limites da cidade de Roma (ROTONDI, 1962).

A utilização desse instituto vem apresentada com muita clareza pela história do cidadão romano Saulo de Tarso, mais conhecido no Ocidente como São Paulo. Em alguns versículos do livro "Atos dos Apóstolos", Lucas conta como, em várias ocasiões, São Paulo - que, mesmo sendo grego de nascimento, era portador da cidadania romana - conseguiu impor a sua condição jurídica nas adversidades em que se viu $^{34}$. O grito civis romanus sum, tantas vezes utilizado por ele, é a

32 As normas que regulam este status privilegiado eram previstas em diversas leis romanas, entre elas, as mais importantes eram a Lex Valeria Horatia de provocatione e as Leges Porciae de provocatione. (ROTONDI, 1962, p. 235 e 268).

33 Uma das Leges Porciae de provocatione proibiu a fustigação ao cidadão, e a Lex lulia de vi publica et privata, em 17 a.C., que proíbe o uso da tortura aos cidadãos. A apuração de crimen lesa maiestatis (crime por atentar contra a majestade do imperador ou do império romano) será, porém, uma exceção a esta lei.

34 Atos dos Apóstolos, 16, 35-37: "Assim que amanheceu, os estrategos mandaram os litores dizer ao carcereiro: põe esses homens em liberdade. O carcereiro transmitiu a Paulo aquelas palavras: os estrategos mandaram dizer que vos pusesse em liberdade. Sai, pois, e ides-vos em paz. Mas Paulo disse aos litores: Açoitaram-nos em público, sem julgamento, a nós que somos cidadãos romanos, meteram-nos na prisão, e agora manda-nos sair às escondidas! - Não esta bem! Venham eles próprios conduzir-nos lá para fora." Atos dos Apóstolos, 22, 25-29: "Mas, quando iam amarrá-lo para ser açoitado, Paulo disse ao centurião de serviço: Tendes autoridade para açoitar um cidadão romano, que nem sequer foi julgado? Ouvindo isso, o centurião correu a avisar o tribuno: Que vais fazer? - disse ele - esse homem é cidadão romano! O tribuno foi ter com Paulo e perguntou-Ihe: Dize-me, tu és cidadão romano? Sou, respondeu ele. O tribuno continuou: eu adquiri por muito dinheiro esse direito de cidadania. Paulo retorquiu: Pois eu já nasci com esse direito. Os que o iam interrogar retiraram-se imediatamente e o tribuno ficou cheio de medo ao saber que tinha mandado prender e agrilhoar um romano." Atos dos Apóstolos, 25, 9-12: "Mas, como desejava capitar as boas graças dos judeus, Festo respondeu: queres subir a Jerusalém para lá seres julgado sobre este assunto, na minha presença? Paulo replicou: Estou perante o tribunal de César. Devo ser julgado aqui. Não fiz mal nenhum aos judeus, como sabes perfeitamente. Mas, se, de fato, sou culpado, se cometi algum crime que mereça a morte, não recuso morrer. Se, porém, não há fundamento nas acusações dessa gente contra mim, ninguém tem o direito de me entregar a eles. Apelo para César! Então, depois de conferenciar com seu o conselho, Festo respondeu: Apelaste para César, irás a César." 
afirmação de um direito perante a autoridade romana, materializado em um forte sistema de garantias jurisdicionais e de proteção do cidadão ${ }^{35}$.

Uma garantia jurisdicional forte também era constituída pelo postliminium - o direito do cidadão romano capturado pelo inimigo ou ilegalmente reduzido à escravidão de reaver sua condição jurídica como antes da captura ou da escravidão, a partir do ingresso no território romano ${ }^{36}$. O postliminium atua sobre todos os vínculos jurídicos do cidadão, menos sobre o matrimônio, considerado como comunhão de vida e baseado na convivência material e na affectio maritalis.

Como é de se esperar, a cidadania não implicava apenas direitos, mas também deveres. O cidadão romano tinha basicamente

35 Outro episódio significativo, nesse âmbito, é o citado por Cícero na obra In Verrem secundae liber $V(62,161-63,163 ; 65,167-65,168)$ : "Quando de repente ordena que o homem seja arrastado da prisão para o meio da praça, seja despido e amarrado e que sejam preparados os azorragues. Aquele pobre coitado clamava dizendo que era cidadão romano, municípe de Compsa; que tinha servido no exército com Lucius Raecius, destacadíssimo membro da cavalaria romana, o qual exercia o comércio em Palermo, e que tudo isso Verre poderia muito bem saber [...]; em seguida ordenou que o homem fosse açoitado com extremo rigor. Um cidadão romano, senhores juízes, era açoitado no meio da praça de Messina e, no entanto, nenhuma outra voz se podia ouvir, a não ser a daquele coitado que, entre golpes dos açoites, dizia: "Sou um cidadão romano!". Evocando assim a sua condição de cidadão, julgava estar evitando os golpes de açoite e afastando de si a tortura. Isto não somente não ocorreu - para que a força dos golpes fosse sustada - mas ainda, quanto mais implorava e quanto mais invocava o título de cidadão, a cruz, a cruz, digo, era preparada para aquele infeliz, aquele coitado que jamais vira tal suplício! Oh doce nome da liberdade! Oh exímio privilégio dos nossos cidadãos! Oh Lei Pórcia e Lei de Sempronius! Oh poder dos tribunos tão profundamente desejado e finalmente conferido ao povo romano! É por caso, pois, a supressão de todas estas garantias que leva o cidadão romano, em uma das Províncias romanas, em uma cidadela de confederados, a ser amarrado e entregue aos golpes de açoite em praça pública por aquele que, através do benefício do povo romano, era revestido das mais altas honras? [...] Tu ousastes mandar crucificar alguém que dizia ser cidadão romano? [...] Homens de baixa condição, de humildes origens vão pelo mar, se dirigem a países nunca vistos antes, onde nem podem ser conhecidos aos habitantes do lugar, onde chegam sem encontrar quem se tutele a identidade deles. Não obstante tudo, confiantes exclusivamente na prerrogativa deles de cidadãos romanos, pensam que estarão seguros [...] têm a esperança ainda de encontrar neste título uma válida proteção em qualquer país que cheguem. Tira esta esperança, tira esta proteção aos cidadãos romanos, anula ainda o socorro inerente nas palavras "sou um cidadão romano!", autoriza um pretor ou quem for que seja a infligir impunemente o suplício que mais lhe agrada a dano de alguém que se proclama cidadão romano, com o pretexto de não conhecer a sua identidade: com uma desculpa como esta terás imediatamente impedido aos cidadãos romanos o acesso a todas as nossas províncias, a todos os reinos, a todos os Estados livres, a toda a terra, sempre amplamente acessíveis aos nossos compatriotas."

Ver sobre o assunto: Gaudemet (2002, p. 186); Cursi (1996). 
duas obrigações em relação ao Estado: o pagamento dos tributos e a prestação de serviço militar (GAUDEMET, 2002). O serviço militar, que por muito tempo foi considerado uma honra e um privilégio, começou a entrar em desuso no final do período da república, quando grande parte dos alistados não eram mais romanos. Tratavam-se de pessoas de diferentes origens que buscavam a cidadania romana ou simplesmente a possibilidade de receber um soldo de Roma. De qualquer forma, por longo tempo, entre os povos conquistados, continuou viva a ideia de que servir ao exército romano seria uma grande honra, motivo de ascensão social e de status (GAUDEMET, 2002) ${ }^{37}$.

Nessa lógica, movida pela busca da honra e da ascensão social, os cidadãos deveriam constantemente demonstrar possuir alguns atributos que caracterizassem o vínculo com a pátria romana, tais como coragem, respeito aos deuses, lealdade e fidelidade, que se contextualizavam como valores máximos, sendo exaltados pelos filósofos e juristas romanos. Entre estes, destaca-se a figura de Marco Túlio Cícero ${ }^{38}$, o qual afirmava que:

Quando o espírito percorre todas as sociedades humanas, não encontra nada mais empolgante que as relações entre nós e a Pátria. Temos amor por nossos pais, por nossos filhos, pelo próximo, por nossos amigos; mas só a Pátria enfeixa todos os amores. Qual o homem de

37 Segundo Nicolet (1999), na concepção romana, os filhos dos ricos seriam sempre os melhores soldados, já que teriam maior interesse em defender a cidade e os benefícios que a classe possuía.

38 Marco Túlio Cícero nasceu em Arpino, em 106 a. C., e morreu em 43 a. C. De família nobre, desenvolveu intensa atividade, seja no campo político (obteve, através do favorecimento da classe patrícia, a nomeação a cônsul, contra o adversário Lúcio Sérgio Catilina), seja no campo judiciário (foi certamente o melhor advogado de Roma). Como cônsul, desmascarou, com as suas Catilinárias, a conjuração que Catilina, líder do partido popular, estava conspirando contra o regime repúblicano. Retirou-se da vida política durante a ditadura de César, sendo desse período a maior parte das suas obras de retórica e filosofia. Voltou a se ocupar de política após o assassinato de César, sendo a favor de Otaviano e contra Marco Antônio, contra quem lançou uma série de violentos ataques. 
bem que vacilaria em morrer por ela, se algo pudesse servir com essa morte? ${ }^{39}$

O sistema jurídico romano previa a perda da cidadania em duas situações: capitis deminutio maxima e media. A primeira hipótese ocorria se o cidadão romano perdesse a sua capacidade nas três situações jurídicas que envolvem a pessoa, ou seja: liberdade, cidadania e família. Nesse caso, a pessoa era reduzida à escravidão ${ }^{40}$. A segunda hipótese se originava do fato de o direito romano não admitir que um cidadão de Roma adquirisse a cidadania de outro povo, acarretando em imediata perda da cidadania, mas mantendo sua liberdade ${ }^{41}$.

As prerrogativas da cidadania romana eram amplas e implicavam diretamente na atividade política, visto que apenas o cidadão podia votar nas assembleias populares e, consequentemente, decidir o futuro de Roma. Essas mesmas prerrogativas, e suas consequências, acabaram tornando inviável a abertura de concessão da cidadania aos não cidadãos em períodos de guerras, levando à ponderação de vários fatores e ao enrijecimento na assimilação de pessoas externas à comunidade.

39 Cic. off. 1,57: "Sed cum omnia ratione animoque lustraris, omnium societatum nulla est gravior, nulla carior quam ea, quae cum re publica est uni cuique nostrum. Cari sunt parentes, cari liberi, propinqui, familiares, sed omnes omnium caritates patria una complexa est, pro qua quis bonus dubitet mortem oppetere, si ei sit profuturus?"

40 Paul. dig. 4.5.11: "Capitis deminutionis tria genera sunt, maxima media minima: tria enim sunt quae habemus, libertatem civitatem familiam. Igitur cum omnia haec amittimus, hoc est libertatem et civitatem et familiam, maximam esse capitis deminutionem: cum vero amittimus civitatem, libertatem retinemus, mediam esse capitis deminutionem: cum et libertas et civitas retinetur, familia tantum mutatur, minimam esse capitis deminutionem constat". Segundo Gaudemet (2002), uma vez retornado a Roma, o cidadão poderia readquirir a situação jurídica como antes de ser feito prisioneiro, através do instituto do postliminium. Para ser beneficiado, era necessário: a) que Roma não reconhecesse a condição de escravo que lhe fora atribuída, coisa que somente aconteceria se a pessoa tivesse sido aprisionada e feita escrava pelo inimigo (eram automaticamente excluídos os vendidos como escravos para o pagamento de dívidas); b) que no ato da prisão ele não tivesse ainda capitulado; c) que ele tivesse efetivamente retornado ao território romano, sem a intenção de retornar ao povo estrangeiro.

41 Recorda Gaudemet (2002) que o De Visscher (1954) faz notar que o mesmo não acontecia com o estrangeiro que viesse receber a cidadania romana. Uma antiga tradição permitia adquiri-la sem ter que renunciar à cidadania de origem. 


\section{Conclusão}

A cidadania romana é caracterizada em toda a existência de Roma pela liberdade ${ }^{42}$, ganhando diferentes aspectos e desdobramentos com as transformações sociais e políticas vivenciadas. A cidadania garantia a manutenção do status naturale do cidadão e trazia em si o valor de participação política à comunidade. Essa participação, inicialmente, foi universal em âmbito masculino, com igualdade de valor dos votos, sendo modificada durante a Dinastia Tarquínia, por Sérvio Túlio, que estabeleceu valor diferente para o voto de cada cidadão, de acordo com fatores como economia, nascimento e carreira.

A extensão da civitas através da concessão de cidadania romana ocorre tendo por base o princípio da civitas augescens e da civitas amplianda ${ }^{43}$. A concepção de expansão da cidadania é presente, desde a origem da cidade, no asilo aos estrangeiros, criado por Rômulo, no Capitólio. Durante a república, continuou-se a sentir a concepção de expansão da cidade por meio das conquistas de povos e cidades, bem como a ampliação da civitas aos povos itálicos e à Gália Transpadana.

A gradual expansão da cidadania romana resultou no paulatino enfraquecimento da distinção entre civis, Latinus e peregrinus, refletindo o universalismo romano através da abertura em relação ao externo e consolidando o universalismo romano por meio do ius.

\section{Referências}

AMIRANTE, Luigi. Una storia giuridica di Roma. Napoli: Jovene, 1991. ARENDT, Hannah. Entre o passado e o futuro. São Paulo: Perspectiva, 2003.

\footnotetext{
42 Vai nessa direção Constant (1819); também Arendt (2003, p. 205), ao afirmar que "[...] tanto na Antiguidade grega como na romana, a liberdade era um conceito exclusivamente político, a quintessência, na verdade, da cidade-estado e da cidadania".

43 Sobre civitas augescens, ver: Pomp. dig. 1,2,2,7; e sobre civitas amplianda, ver: lust. cod. 7,15,2.
} 
BELLINI, Vincenzo. Sulla genesi e la struttura delle leghe nell'Italia arcaica. Liège: RIDA, 1961.

BENVENISTE, Émile. Le vocabulaire des institutions indo-européennes, I. Économie, parenté, société. Paris: Minuit, 1969.

CARLE, Giuseppe. Le origini del diritto romano. Torino: Fratelli Bocca, 1888.

CATALANO, Pierangelo. Alcuni concetti e principi giuridici romani secondo Giorgio La Pira. In GAROFALO, Luigi; BURDESE, Alberto. II ruolo della buona fede oggettiva nell'esperienza giuridica storica e contemporanea. Padova: CEDAM, 2003.

CATALANO, Pierangelo. Aspetti spaziali del sistema giuridico-religioso romano Mundus, templum, urbs, ager, Latium, Italia. In: Aufstieg und Niedergang der römischen Welt. Geschichte und Kultur Roms im Spiegel der neueren Forschung II.16.1. Berlin, 1978.

CATALANO, Pierangelo. Contributi allo studio del diritto augurale. Torino: Giappichelli, 1960.

CATALANO, Pierangelo. La divisione del potere in Roma (A proposito di Polibio e Catone). Studi in onore di Giuseppe Grosso VI. Torino: Giappichelli, 1974a.

CATALANO, Pierangelo. Linee del sistema sovrannazionale romano. Torino: Giappichelli, 1965.

CATALANO, Pierangelo. Populus romanus quirites. Torino: Giappichelli, 1974.

CATALANO, Pierangelo. Promemoria. In: SEMINARIO INTERNAZIONALE DI STUDI STORICI, 27.,2007, Roma, "Da Roma alla terza Roma". Roma, 2007. Annali... Roma, 2007.

CATALANO, Pierangelo. Seduta preliminare. In: SEMINARIO INTERNAZIONALE DI STUDI STORICI "Da Roma alla Terza Roma" La nozione di "romano" tra cittadinanza e universalità. Anali... Napoli: Scientifiche Italiane, 1982. p. XXI - XXIV. 
CERAMI, Pietro; CORBINO, Alessandro. Storia del diritto romano. Messina: Rubettino, 1996.

COLI, Ugo. II diritto pubblico degli Umbri e le tavole Eugubine. Milano: Giuffrè, 1958.

COLOGNESI, Luigi Caprogrossi. Lezioni di storia del diritto romano: Monarchia e Repubblica. Napoli: Jovene, 2004.

CONSTANT, Benjamin. De la liberté des anciens comparée à celle des modernes: discours prononcé à l'Athénée royal de Paris. [S.I.: s.n.], 1819.

COSENTINI, Cristoforo. Studi sui liberti. Catania: [s.n.], 1948. v. I.

COSENTINI, Cristoforo. A proposito di una recente ipotesi sull'origine delle forme civili di manumissione. In: Seminario Giuridico dell'università di Catania , 2, 1948, Catania. Annali... Catania: Univ. Catania, 1948.

COSENTINI, Cristoforo. Ancora sull'origine e l'efficacia delle forme civili di manumissione. In: Miscellanea romanistica. Catania: [s.n.], 1956.

COSENTINI, Cristoforo. Liberti (diritto romano). In: Novissimo Digesto Italiano. Torino: Giappichelli, 1957. v. 9.

COSTA, Emilio. Storia del diritto pubblico romano. Firenze: Barbera, 1906.

CRIFÒ, Giuliano. Asilo (diritto di). In: Enciclopedia del diritto. Milano: Giuffrè, 1958. v. 3.

CRIFÒ, Giuliano. Cittadinanza (diritto romano). In: Enciclopedia del diritto. Milano: Giuffrè, 1960. v. 7.

CRIFÒ, Giuliano. Civis: la cittadinanza tra antico e moderno. Roma: Laterza, 2003.

CRIFÓ, Giuliano. Libertà e uguaglianza in Roma antica: l'emersione storica di una vicenda istituzionale. 2. ed. Roma: Bulzoni, 1984.

CURSI, Maria Floriana. La struttura del "postliminium" nella repubblica e nel principato. Napoli: Jovene, 1996. 
DE FRANCISCI, Pietro. Primordia civitatis. Roma: Apollinaris, 1959.

DE MARTINO, Francesco. Storia della costituzione romana. Napoli: Jovene, 1973.

DE VISSCHER, Fernand. La dualité des droits de cité et la "mutatio civitatis". Napoli: Studi de Francisci, 1954. v. 1.

DEVOTO, Giacomo. La città e lo stato degli Umbri:L'Umbria nella storia, nella letteratura, nell'arte. Bologna: Zanichelli,1954.

ELLUL, Jacques. Histoire des institutions: L'Antiquité. Paris: Quadrige/ PUF, 1999.

ERNOUT, Alfred; MEILLET, Antoine. Dictionnaire étymologique de la langue latine. Paris: Librairie C. Klincksieck,1959.

GAUDEMET, Jean. Les institutions de l'antiquité. 7. ed. Paris: Montchrestien, 2002.

GIERKE, Otto Friedrich von. Das deutsche Genossenschaftsrecht III. Graz: Akademischer Verlag, 1954.

GIOLO, Orsetta; PIFFERI, Michele. Diritto contro, meccanismi giuridici di esclusione dello straniero. Torino: Giappichelli, 2009.

GUARINO, Antonio. Diritto privato romano. Napoli: Jovene, 1997.

GROSSO, Giuseppe. Lezioni di Storia del diritto romano. Torino: Giappichelli, 1965.

GROSSO, Enrico. Le Vie della cittadinanza: le grandi radici: i modelli storici di riferimento. Padova: Cedam, 1997.

GÜNTHER, Rigobert. Wirtschaftliche und soziale differenzierung im ältesten Rom. Leipzig: WZ, 1957/1958. v. VII.

IMBERT, Jean. Le postliminium. Paris: Montchrestien, 1944.

JHERING, Rudolph. Geist des römischen rechts. Leipzig: Breitkopf \& Härtel, 1877-1880. 
KUNKEL, Wolfgang. Linee di storia giuridica romana. Napoli: Scientifiche Italiane, 1972.

LE GALL, Joel. Le tibre fleuve de Roma dans l'antiquité. Paris: PUF, 1953.

LUBRANO, Micaela. Persona e homo nell'opera dio Gaio: elementi concettuali del sistema giuridico romano. Torino: Giappichelli, 2002.

MOMMSEN, Theodor. Römische Staatsrecht. Leipzig: Teubner, 1887.

NICOLET, Claude. II mestiere di cittadino nell'Antica Roma. Roma: Riuniti, 1999.

NIEBUHR, M. Barthold Georg. Römische geschichte. Berlin: Reimer, Georg, 1811.

NOCERA, Guglielmo. II binomio pubblico-privato nella storia del diritto. Napoli: Scientifiche Italiane, 1992.

ORESTANO, Riccardo. II problema delle persone giuridiche in diritto romano. Torino: Giappichelli, 1968.

PEPE, Leo. Popolo (dir. rom.). In: ENCICLOPEDIA del diritto. Napoli: Giuffrè, 1985. v. 34.

ROBLEDA, Olis. Il diritto degli schiavi nell'antica Roma. Roma: Gregoriana Press, 1976.

ROTONDI, Giovanni. Leges publicae populi romani: elenco cronologico con una introduzione sull'attività legislativa dei comizi romani. Milano: G. Olms, 1962.

RUBINO, Joseph. Über den Entwickelungsgang der römischen Verfassumg bis zum Höhepunkte der Republik. Cassel: Krieger, 1839.

SERRAO, Feliciano. Classi, partiti e legge nella repubblica romana. Pisa: Pacini, 1975.

SERRAO, Feliciano. Diritto privato economia e società. Napoli: Jovene, 2006. 
SHERWIN WHITE, Adrian Nicholas. The Roman citizenship. Oxford: Clarendon Press, 1939.

STADTMÜLLER, Georg. Geschichte des Völkerrechts. Hannover: Schroedel Verlag, 1951. Teil I: Bis zum Wiener Kongreß.

TONDO, Salvatore. Profilo di storia costituzionale romana. Milano: Giuffrè, 1981.

WATSON, Alan. The law of persons in the later Roman Republic. Oxford: Clarendon Press, 1967.

Recebido em: 27/07/12

Aprovado em: 20/02/13 